\title{
Expectations About Management Consultancy Services: Testing the Assumption of Equivalence Across Australian and Singaporean Firms
}

\author{
Albert Caruana, $\mathrm{PhD}$ \\ B. Ramaseshan, PhD \\ Michael T. Ewing, DComm \\ Fariba Rouhani, BComm
}

\begin{abstract}
Consultaney firms have adopted a higher international profile as they follow the increased global presence of many businesses. The provision of a quality offering by providers of consultancy services necessitates a clcar understanding of customer expectations across countries. The expectations items in SFRVQUAL have been applied to samples of firms in Australia and Singapore to test for the equivalence of the expectations construct. Multiple sample LISREL analysis is carried out on data from the two countries. The results indicate an absence of construct equivalence. Implications and suggestions for future research are provided. Article coppes a wilable fen a fee from The Hawerth Document Delivery Service: J-800-3+2-9678. E-mail address: getinfouhaworthpressinc.coml
\end{abstract}

\section{INTRODUCTION}

As business has become more global, many management consultancy firms have also increasingly sought to offer their services interna-

Albert (aruana is affiliated with the Department of Varketing. University of Malta, Msida MSD 06 Malta. He is currently visiting from the Department of Marketing. University of Malta. Malta. B. Ramaseshan. Michael T. Ewing. and Fariha Rouhani are affiliated with the School of Marketing. Curtin University of Technology. Perth, Western Australia.

Address currespondence 10: Albert Cartana. Department of Marketing. L'niversity of Malta, Msida MSD ()6, Malta. E-mail: acar(a cet.um.edu.mt

Joumal of Protessional Services Marketing. Vol. 18(1) 1998

C 1998 hy The Hawnrth Press. Inc. All rights reserved. 
tionally either through associate companies in the different countries or by opening branch offices. Overall, the demand for professional consulting services throughout the Western world has witnessed a dramatic increase (Fisher, 1989). Professional services are complex, their effects are often delayed, and usage is often irregular (Hite and Fraser 1988). Many management consultancy firms have sought to gain competitive advantage by differentiating their offering and focusing on service quality. Definitions of service quality revolve around the idea that it is the result of the comparison that customers make between their expectations about a service and their perception of the way the service has been performed (Lewis and Booms, 1983; Lehtinen and I.ehtinen 1982, Grönroos, 1984; Parasuraman, Zeithaml and Berry, 1985; 1988). Perceptions are defined as consumers' beliefs concerning the service received or experienced while expectations are what customers feel a service provider should offer. This definition of service quality has enabled the development of SERVQUAL. This instrument uses twenty-two matched pairs of items to measure the gaps between client expectations and client perceptions and provides researchers with the possibility of measuring the expectations-performance gap (Gap 5) ostensibly composed of five determinants.

\section{PURPOSE OF THE STUDY}

The work by Parasuraman, Zeithaml and Berry $(1985 ; 1988)$ has proved very popular and SERVQUAL has generated much research and application across different industry sectors and countries. However, many comparisons have been undertaken that do not consider whether the results are really comparable. When one samples across a number of cultures the main conceptual challenge is to establish equivalence (Bond, 1988). Equivalent measurement is obtained when the relations between observed scores and latent constructs are identical across relevant groups (Drasgow and Kanfer, 1985). It is necessary and possible to investigate construct equivalence using multiple group LISREL.

Given the current conceptualisation of service quality, the scores obtained for the expectation items have a critical effect on the results of the analysis of difference scores. Moreover it is important for management consultancy service providers that operate across countries to know whether they need to deliver the same levels of service 
across countries or whether it may be more cost effective to adapt service provision according to the expectations in the different countrics.

We set out to investigate the equivalence of the expectations construct in two different countries and begin with the overall test of equality of covariance structures. The null hypothesis is that there is no difference between the expectations of senior managers in the Singaporean (s) and Australian (a) samples and that the covariance matrices $\left(\sum\right)$ from the two populations are equivalent, i.e.:

$$
H_{\Sigma}: \Sigma \mathrm{s}=\Sigma \mathrm{a}
$$

A failure to reject the null hypotheses can be interpreted as evidence of invariance across groups and allows populations to be treated as one. In this case the covariance matrices can be pooled and subsequent investigations can be based on single group analysis. Rejection of the hypothesis necessitates testing of increasingly restrictive hypothesis in order to identify the source of non equivalence. The next hypotheses would test whether the number of factors $(x)$ underlying the expectations construct is invariant across countries. The literature dealing with the expectations construct in SERVQUAI is not sufficiently clear as to the factor structure of this construct. However since the difference scores in SERVQUAL have been said to consist of five dimensions (Parasuraman, Zeithaml and Berry, 1988: 1991; 1994); of more than five (cf. Babakus and Mangold, 1989): and as being unidimensional (cf. Cronin and Taylor 1992; 1994; Brown, Churchill and Peter, 1993): two hypotheses relating to the number of factors will be tested, i.e.:

$$
\begin{aligned}
& \mathrm{H} \times A: \Lambda(s)=1=\Lambda(\mathrm{a})=1 \\
& \mathrm{H} \times \mathrm{B}: \Lambda(s)=5=\Lambda(\mathrm{a})=5
\end{aligned}
$$

If it results that the number of factors across the groups is equivalent, it will be worthwhile to proceed to three further test of invariance. The first of these tests the hypotheses that the scales of identical constructs have equal factor loadings, i.e.:

$$
\mathrm{H} \Lambda: \Lambda(\mathrm{s})=\Lambda(\mathrm{a})
$$


The second tests the more restrictive hypotheses that scales not only have equal loadings but also have equal error. i.e.:

$$
H \wedge \Theta: \Theta \delta(s)=\Theta \delta(a)
$$

The most restrictive test is the hypotheses that holds that the scales not only have equal factor loadings and error but also equal variancecovariance matrices, i.e.:

$$
H \Lambda \Theta \Phi: \Phi(s)=\Phi(a)
$$

To investigate these hypotheses, research is carried out among senior managers of firms in Australia and Singapore to determine their expectations of the services provided by management consultants. Implications are drawn and suggestions for ongoing research are offered.

\section{METHODOLOGY}

To be able to investigate the expectations of senior managers, a research design was employed that involved postal questionnaires to a cross-section of marketing directors of the top firms listed on the Australian and Singaporean Stock Exchange. Mail questionnaires lave the advantages of covering a wide geographical area cost effectively while respondents can complete the questionnaires at their own convenience (Sekaran, 1992). Respondents were assured of confidentiality and anonymity and a pre-paid envelope was included. A cover letter accompanicd each questionnaire explaining the purpose and the importance of this study and requested assistance and a quick response.

Expectations were measured using the 22 expectation items in SERVQUAL. The original items were amended, where necessary, to reflect the situation for management consultants. Fach item was described by 7-point Likert type scales anchored by $1=$ Strongly disagree to $7=$ Strongly agree. Higher scores on this scale (when reverse scored items are suitably amended) indicate higher levels of expectations. The final questionnaire was made up of twenty-two items that consisted of measures for expectations together with three classificatory variables.

One thousand postal questionnaires were sent to the marketing 
directors of the top companies listed on the Australian Stock Exchange, ranked by their market capitalisation in carly December 1994. This information was obtained from the Shareholder: The Handbook of Australian Public Companies, 1995. Similarly, a further 440 questionnaires were sent to the top companies listed on the Singaporean Stock Exchange. By the cut off date. the total number of usable questionnaires was 210 and 104 representing $21.0 \%$ and $23.6 \%$ respectively.

An "extrapolation procedure" was used to assess non-response bias. This assumes that "late" respondents are similar to the "theoretical" non respondents (Armstrong and Overton, 1977). Independent $t$-tests where used to determine whether significant differences between the sum of the expectations items diffored between the two sub-samples consisting of respondents in the first and last quartile. No significant differences were found between the two sub-samples for this variable. The results suggest that there appears to be no difference between respondents and non-respondents for the variables under study and the sample can be considered sufficient to draw conclusions about the two populations for the issue under study.

\section{ANALYSIS}

The profiles of the respondents from Australia and Singapore indicated that the majority of the companies have been operating for over twenty-one years. The main business activities differed in the two countries, with manufacturing being the most widespread activity in both Australia and Singapore.

The covariance matrices for the expectation items of both samples were computed. Multiple sample analysis in LISREL VII (Jöreskog and Sörbom. 1989) was used to analyse the resultant matrices from the two samples simultaneously. To test the first hypotheses of the study, each item is taken to represent one factor (a 22-factor model), the factor loading matrix is taken to be an identity matrix $(\mathrm{LX}(\mathrm{s})=\mathrm{LX}(\mathrm{a})=$ I), and the error variance-covariance matrix is a null or zero matrix $(T D(s)=T D(a)=0)$. The model specification for the Australian sample is exactly the same as that for the Singaporean sample and the factor covariance matrix is set as invariant (PH(s) $=\mathrm{PH}(\mathrm{a})$ ). (The LISREL input appears in Appendix A.) To test the second hypotheses of common factors, the one-factor and five-factor models are tested 
and these involved the manipulation of the LX matrix with the PH and TD matrices set free. The results obtained are shown in Table 1.

Although it is not necessary to look at the three last hypotheses given that the first three were rejected, these have been computed for completeness sake, using a unidimensional model and are also shown in Table 1.

\section{CONCLUSIONS}

The results indicate that there is a difference in expectations between Singaporean and Australian managers about the service they expect from management consultants. Moreover, since service quality is often conceptualised as the difference between the expectation scores and performance, it is likely that the difference scores for service quality in the two countries will also be different. It appears that management consultants cannot rely on a belief of one international level of expectations. They need to understand the different expectation levels of their customers in the different countries in which they operate and manage their service delivery accordingly. Failure to do so may result in losing out in some markits and overdelivering and unnecessary costs in others.

The study has a number of limitations. For a start it is not clear whether the expectations construct is unidimensional or five dimensional. This may be having an effect on the results obtained for the second, and subsequent hypothesis, of this study. Secondly, by their very nature expectations scores are necessarily skewed and results

TABLE 1. Summary of Results for Hypothesis Tested

\begin{tabular}{lccc} 
Hypothesis & \multicolumn{1}{c}{$\chi^{2}$} & df & p value \\
\hline $\mathbf{H}_{\Sigma}$ & 991.27 & 253 & 0.000 \\
HXA & 2011.62 & 419 & 0.000 \\
$\mathbf{H} \times B$ & 2266.49 & 222 & 0.000 \\
\hline $\mathbf{H} \wedge$ & 2082.54 & 440 & 0.000 \\
$\mathbf{H} \wedge \Theta$ & 2355.46 & 462 & 0.000 \\
$\mathbf{H} \wedge \Theta \Phi$ & 2358.81 & 463 & 0.000
\end{tabular}


must be interpreted with caution. Thirdly, the conceptualisation of expectations used views these as more or less fixed "normative" standards of future wants that are "similar to the ideal standard in CS/D) literature" (Zeithaml, Berry and Parasuraman. 1991). Finally, the relatively small sample sizes are a function of time, budget, and distance constraints, and these may have an affect on the extent of precision in the analysis. The samples are based on convenience and any generalisations must be done with caution as sclection error must be appreciated when generalising to the population from such a sample (Churchill, 1979). However, this type of sampling may be used with confidence when, as is the case in this study, the emphasis is on exploratory research.

Teas (1993) has argued that the original definition of expectations used in the service quality literature is "vague" and can have several meanings. Following the results of a number of replication studies, Parasuraman. Zeithaml and Berry (1991) have reassessed the expectations side of their model and respecify expectations into two: "desired" wants described as "the extent to which customers believe a particular attribute is "essential" for an excellent service company" and "minimum service expectations" (Parasuraman, Zeithaml and Berry, 1994). Research leading to the development of a clearer conceptualisation and resultant factor structure of the expectations construct is necessary. Future research could also focus on an analysis of the equivalence of the different types of expectations for different services and across countries.

\section{REFERENCES}

Armstrong J. S., Overton I. S., (1977), Estimating non response hias in mail surveys. Journal of Marketing Research. XIV, (August). 396-402.

Babakus E.. Mangold G. (1989), Adapting the SERVOUAI scale to the health care environment: An empirical assessment. in Bloom P. et al., (eds) AMA Educators Proceedings, Chicago. IL. American Marketing Assuciation.

Bond M. H. . (1988) Finding universal dimensions of individual variation in multicultural studies of values: The Rokeach and Chinese value surveys, lommal of Personaliz and Social Psychology, 55, 6, 1009-1015.

Broun T. J. Churchill G. A Jr.. Peter J. P. (1993). Improving the Measurement of Service Quality, Jommal of Retailing, 69.1. (Spring). 127-1.34.

Churchill G. A. Jr., (1979). A Paradigm for Developing Belter Measures of Marketing Constructs. Jounal of Marketing Research. 16. February, 6:-73.

Cronin J. J. Taylor S. A., (1992). Measuring Service Qualit: A Re-examination and Extension. . Fom of Marketing, 56. (July). 55-68. 
Cronin J. J., Faylor S. A., (1994), SERVPERF versus SFRVQUAL: Reconciling Performance based and Perception based-Minus-Fxpectation Measurements of Strvice Quality. Jotund of Marketing. 58. (January), 125-131.

Drasgow F. Kanfer R., (1985) Equivalence of psyclubligical measurement in heterogeneous populations. Journal of Applied Psychology, 70. 4. 662-680.

Fishtr Anne, (1989). The Ever-Bigger Buom in Consulting, Fortume, 119. April, $59-68$.

Grönroos (.. (1984), A Service Quality Model and its Market Implications, European Joumal of Markening. 18, 4, 36-44.

Hite R. and Fraser (.. (1988). Meta-Analysis of Attitudes Tou ard Advertising by Professional. Ioumal of Marketing. 52, July, 95-105.

Joreskog K. G.. Sörbom D. (1989). LISREL 7: A guide to the program and applications, 2nd edn., (hicago: IL, SPSS Inc.

Lehtinen U. Lehtinen J. R., (1982), Service quality-t study of dimensions. Unpublished working paper. Service Management Institute: Helsinki. 439-460.

Lewis R. (., Buonss B. H., (1983), The Marketing Aspects of Service Quality, in Berry L. L.. Shostasck G. and Upah G., (eds.), Emerging persectives in serice markering, Chicilgo: American Marketing Association. 99-107.

Parasuraman A.. Zeithaml V. A. Berry L. L., (1985), A Conceptual Model of Service Quality and its Implication for Future Research. Jownal of Marketing. 49, (April), $41-50$.

Parasuraman A.. Zeithaml V. A, Berry L. L., (1988), SERVQUAL: A Multiple-Item Scale for Measuring Consumer Perceptions of Service Quality. Iotmal of Retailing, 64, 1. (Spring), 12-40.

Parasuraman A.. Zeithaml V. A. Berry L. L., (1991), Refinement and Reassessment of the SERVQUAL. Scile, Joumal of Retailing, 67. 4, 421)-450.

Parasuraman A.. Zeithaml V. A, Berry L. L., (1994), Reassessment of Expectations as a Comparison Standard in Measuring Service Quality: Implications for Further Research, Journal of Marketing, 58. (January), 111-124.

Sekaran, U. (1992) Research Methods for Business: A Skilled Building Approach, 2nd edn. John Wiley \& Sons, Inc., Toronto.

Shareholder: The Handbook of Australian Public Companies, (1995), 8th edn, Statford McWilliams. Sydney.

Teas R. K.. (1993). Expectations. Performance Evaluation and Consumers" Perception of Quality, Jounal of Marketing, 57. (October), 18-34.

Zeithaml V. A.. Berry L. L.. Parasuraman A. (1991), An Empirical Examination of Relationships in an Extended Service Quality Model, Marketing Science Institute, Workiıg paper No. 9()-122. Cambridge: MA. 


\section{APPENDIX. LISREL Input for $\mathrm{H}$ :}

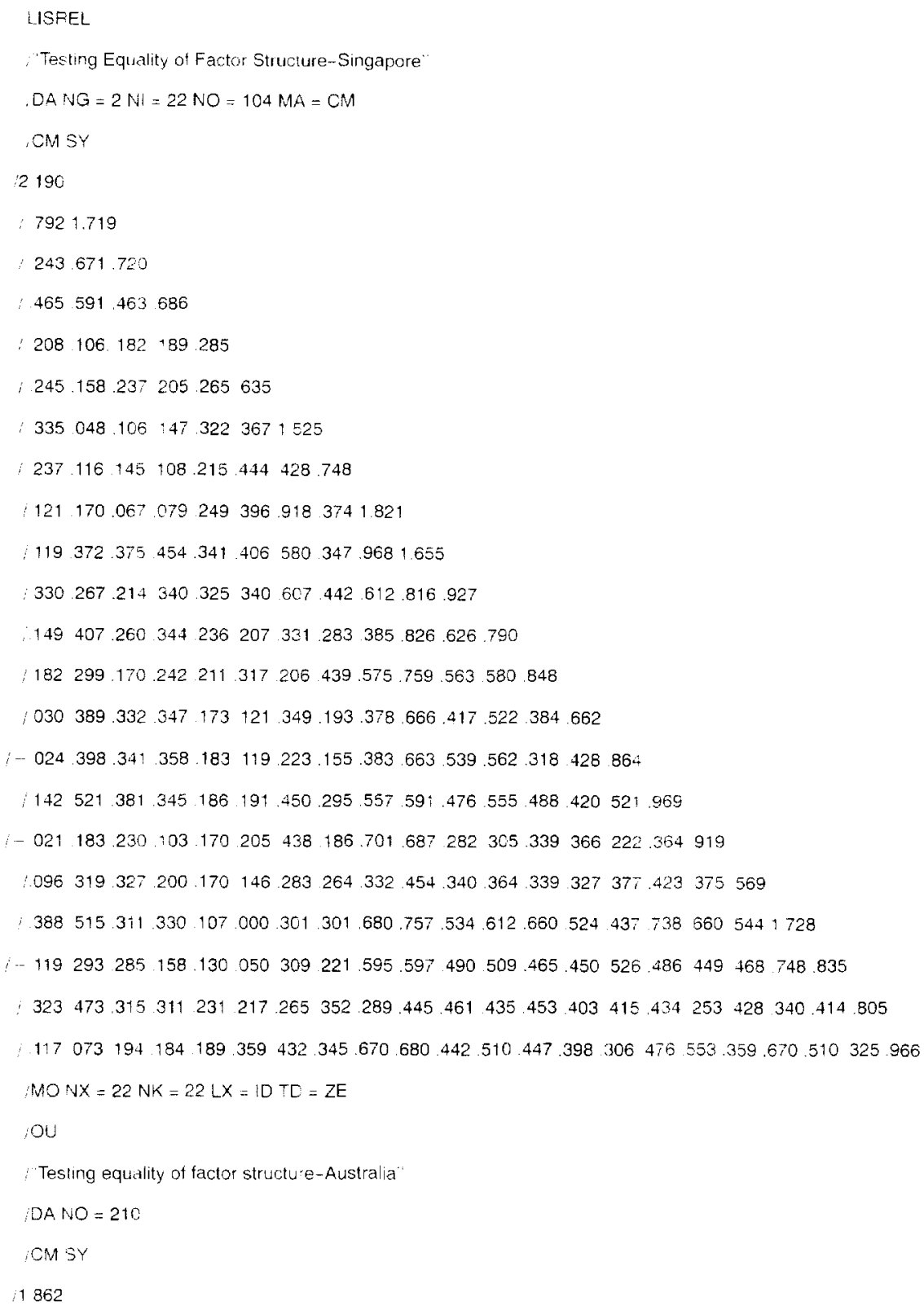




\section{APPENDIX (continued)}

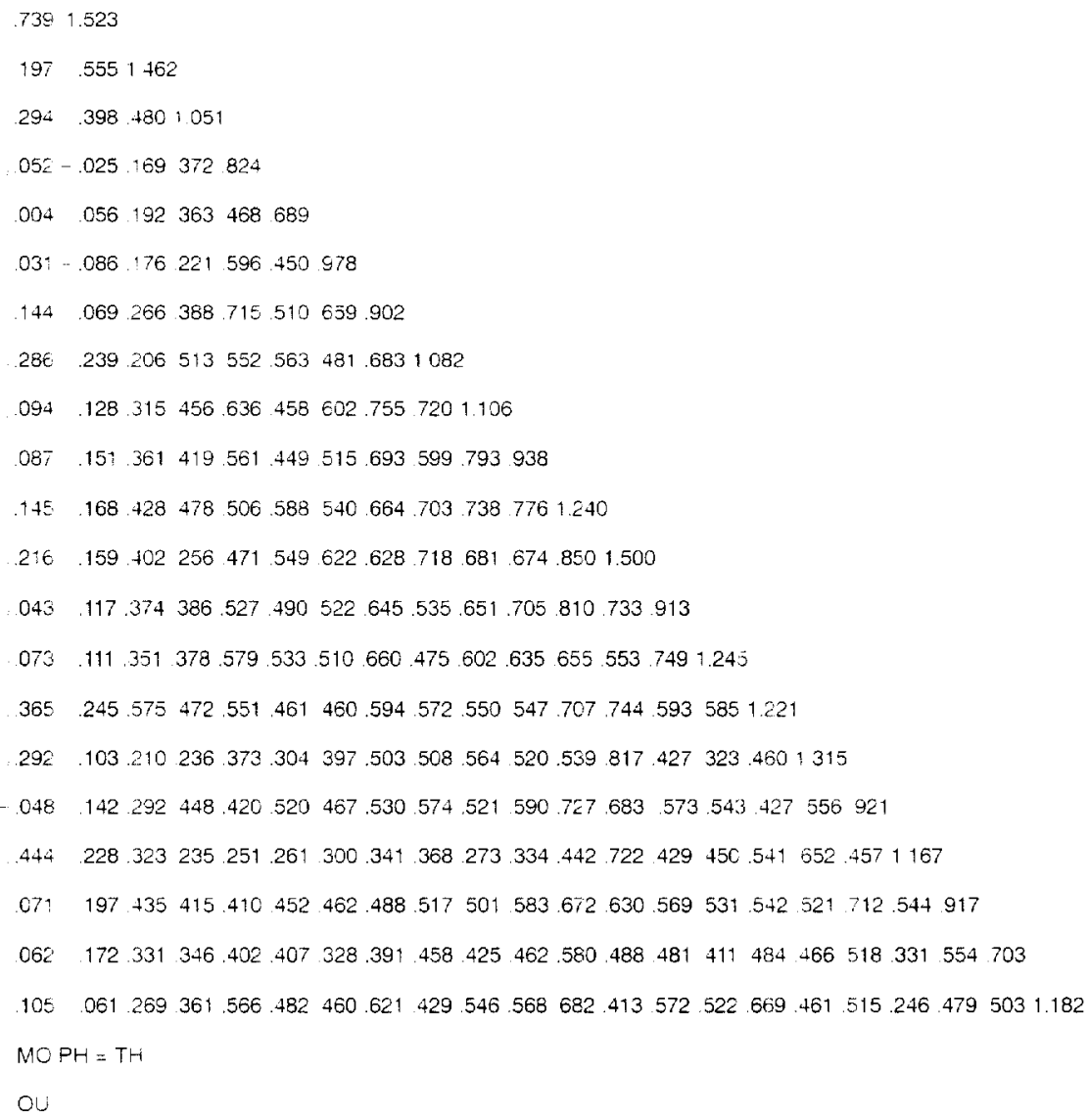

